\title{
STUDI KINETIKA ADSORPSI AI-MCM 41 TERHADAP METILEN BIRU
}

\section{THE KINETICS STUDY OF Al-MCM 41 TO METHYLENE BLUE ADSORPTION}

\author{
Mustofa Ahda ${ }^{1}$ Sutarno $^{2}$, Eko Sri Kunarti ${ }^{2}$ \\ ${ }^{1}$ Fakultas Farmasi Universitas Ahmad Dahlan \\ Jln. Prof. Dr. Soepomo Yogyakarta, Telp. (0274) 379418 \\ ${ }^{2}$ Fakultas MIPA, Kimia, Universitas Gadjah Mada \\ Jln. Kaliurang km 5,5 Yogyakarta, Telp. (0274) 513339 \\ Email: mustofa_ahda@yahoo.com
}

Submitted: 17-12-2015

Reviewed: 15-01-2016 Accepted: 02-05-2016

\begin{abstract}
ABSTRAK
Telah dilakukan sintesis dan studi kinetika Adosorpsi Al-MCM 41 terhadap metilen biru. Pengamatan kinetika adsorpsi merupakan parameter yang sangat penting dalam proses adsorpsi. Hal ini dikarenakan semakin tinggi kinetika adsorpsi maka adsorpsi akan berjalan semakin cepat. Hasil karakterisasi Al-MCM 41 memiliki tebal dinding Pori 15,173 Å,Volume Pori 0,584 cm $/ \mathrm{g}$, Diameter Pori 30,446 ̊., Luas Permukaan 995,513 $\mathrm{m}^{2} / \mathrm{g}$. Hasil Kinetika adsorpsi Al-MCM 41 terhadap metilen biru mengikuti kinetika adsorpsi pseudo orde dua dengan nilai koefisien determinasi $\left(r^{2}\right)$ sebesar 0,999 dan nilai konstanta laju adsorpsi Al-MCM 41 sebesar $10^{-2} \mathrm{~g} \cdot \mathrm{mg}^{-1} \cdot \mathrm{menit}^{-1}$.
\end{abstract}

Kata kunci: Al-MCM 41, karakterisasi MCM 41, kinetika adsorpsi

\section{ABSTRACT}

The synthesis and kinetics studies of Al-MCM 41 of the methylene blue adsorption have been done. The observations of the adsorption kinetics are very important parameter in the adsorption process. This is the higher of adsorption kinetics tend to faster adsorption process. The results of characterization of Al-MCM 41 have a wall thickness is $15.173 \AA$, Pore Volume Pore is $0.584 \mathrm{~cm}^{3} / \mathrm{g}$, Pore Diameter is $30.446 \AA$, Surface Area is $995.513 \mathrm{~m}^{2} / \mathrm{g}$. The results of the adsorption kinetics of AlMCM 41 to methylene blue adsorption follows pseudo second order with coefficient of determination $\left(r^{2}\right)$ value of 0.999 and the value of adsorption rate constant of Al-MCM 41 is $10^{-2} \mathrm{~g} \cdot \mathrm{mg}^{-1} \cdot \mathrm{min}^{-1}$.

Keywords: Al-MCM 41, characterization of MCM 41, adsorption kinetics

\section{PENDAHULUAN}

MCM 41 dapat disintesis dengan surfaktan cetiltrimetilammonium bromida (CTAB) yang berfungsi sebagai zat pengarah struktur dalam membentuk material berstruktur heksagonal (MCM 41), kubus (MCM-48) dan lamelar (MCM-50). MCM 41 merupakan material mesopori yang memiliki susunan heksagonal yang terbentuk oleh matriks silika seperti sarang lebah (Kim dkk.,1995). Park dkk. (2007) menyatakan bahwa MCM 41 memiliki luas permukaan yang tinggi (>1000 m²/g) dan pori heksagonal yang tertata seragam. Struktur MCM 41 terdiri dari susunan heksagonal dengan ukuran diameter pori sekitar 15-100 A yang tergantung pada sifat cetakan (template) dan kondisi sintesis (Das dkk.,1999). Ukuran pori dan situs aktif pada kerangka MCM 41 ini yang dapat mempengaruhi kemampuan adsorpsi MCM 41.

Proses adsorpsi terjadi pada permukaan pori adsorben, sehingga adsorbat dalam cairan akan mengalami 3 proses: (1) Migrasi adsorbat dari larutan ke permukaan adsorben. (2) Difusi dari permukaan adsorbat kedalam melalui pori adsorben, (3) dan proses adsorpsi adsorbat pada situs aktif 
yang ada pada adsorben. Tahapan dalam proses adsorpsi ini menyebabkan adanya perbedaan kecepatan adsorpsi oleh setiap adsorben. Proses kinetika ini bertujuan untuk melihat laju proses adsorpsi yang dilakukan oleh adsorben terhadap adsorbat. Proses kinetika ini yang akan dibahas sesuai model kinetika pseudo orde satu yang dikembangkan oleh Lagergren (Ho dan McKay, 1999) dan pseudo orde dua dari Ho (2006). Model kinetika pseudo orde satu yang dikemukakan oleh Lagergren didasarkan terhadap bertambahnya adsorbat yang teradsorpsi pada padatan sebagai fungsi waktu, secara umum dinyatakan seperti persamaan :

$$
\ln \left(\mathrm{q}_{\mathrm{e}}-\mathrm{q}_{\mathrm{t}}\right)=\ln \mathrm{q}_{\mathrm{e}}-\mathrm{k}_{1} \mathrm{t}
$$

Kemudian dibuat grafik antara $\ln \left(\mathrm{q}_{\mathrm{e}}-\mathrm{q}_{\mathrm{t}}\right)$ vs $\mathrm{t}$, maka diperoleh harga $\mathrm{q}_{\mathrm{e}}$ (terhitung) dan $\mathrm{k}_{1}$, dimana $\mathrm{q}_{\mathrm{e}}$ ialah jumlah adsorbat yang terserap pada kesetimbangan $(\mathrm{mg} / \mathrm{g}), \mathrm{q}_{\mathrm{t}}$ ialah jumlah adsorbat yang terserap pada waktu $\mathrm{t}$ dan $\mathrm{k}_{1}$ merupakan konstanta laju adsorpsi orde satu (menit ${ }^{-1}$ ). Persamaan pseudo orde dua yang dikembangkan Ho didasarkan terhadap laju adsorpsi pada fase padatan, yang dinyatakan dengan persamaan :

$$
\frac{\mathrm{t}}{\mathrm{q}_{\mathrm{t}}}=\frac{1}{\mathrm{q}_{\mathrm{e}}^{2} \mathrm{k}_{2}}+\frac{1}{\mathrm{q}_{\mathrm{e}}} \mathrm{t}
$$

Kemudian dibuat grafik antara $\left(\mathrm{t} / \mathrm{q}_{\mathrm{t}}\right)$ vs $\mathrm{t}$, maka diperoleh harga $\mathrm{q}_{\mathrm{e}}$ (terhitung) dan $\mathrm{k}_{2}$, dimana $\mathrm{q}_{\mathrm{e}}$ ialah jumlah adsorbat yang terserap pada kesetimbangan $(\mathrm{mg} / \mathrm{g}), \mathrm{q}_{\mathrm{t}}$ ialah jumlah adsorbat yang terserap pada waktu $\mathrm{t}(\mathrm{mg} / \mathrm{g})$ dan $\mathrm{k}_{2}$ merupakan konstanta laju adsorpsi orde dua $\left(\mathrm{g} \cdot \mathrm{mg}^{-1} \cdot \mathrm{menit}^{-1}\right)$.

Berdasarkan kedua model kinetika pseudo satu dan pseudo 2 ini kita dapat melakukan pengamatan Al-MCM 41 mengikuti model kinetika pseudo satu atau 2. Penentuan kinetika adsorpsi dapat digunakan untuk menentukan orde dan nilai konstanta kinetika adsorpsinya, dimana semakin besar orde dan konstanta adsorpsi maka kemampuan adsorpsi akan semakin besar.

\section{METODE PENELITIAN Alat dan Bahan}

Alat-alat yang digunakan dalam penelitian ini adalah beaker plastik, kaca arloji, erlenmeyer, penyaring Buchner, pipet tetes, labu ukur, pipet ukur dan termometer, serta didukung oleh peralatan seperti neraca analitik (Mettler AE 160), pengaduk magnetik, furnace (Fischer Scientific $655 \mathrm{~K}$ ), desikator, autoklaf, tabung sentrifugasi, sentrifugasi, spektrofotometer inframerah (Shimadzu FTIR 8201 Prestige 21), difraktometer sinar-X (Simadzu XRD 6000), Surface Area Analyzer (Quantachrome NovaWin2 version 2.2), spektrofotometer UV-Visibel (Hittachi U-2010). Bahan-bahan yang digunakan dalam penelitian ini meliputi: natrium silikat $\mathrm{Na}_{2} \mathrm{SiO}_{3} .9 \mathrm{H}_{2} \mathrm{O}\left(27 \% \mathrm{SiO}_{2}, \mathrm{Merck}\right)$, natrium aluminat $\left(\mathrm{Al}_{2} \mathrm{O}_{3} \cdot \mathrm{Na}_{2} \mathrm{O}\right.$, Merck), cetiltrimetilammmonium bromida (CTAB, Merck), $\mathrm{CH}_{3} \mathrm{COOH}$ (Merck), akuades, dan metilen biru (CI. 52015, Merck).

\section{Jalannya Penelitian \\ Sintesis Al-MCM 41}

Material MCM $41(\mathrm{Si} / \mathrm{Al}=23)$ disintesis dengan komposisi molar pada reaksi campuran 1 $\mathrm{SiO}_{2}: 0,022 \mathrm{Al}_{2} \mathrm{O}_{3}: 0,25 \mathrm{CTAB}: \mathrm{O}, 31 \mathrm{Na}_{2} \mathrm{O}: 50 \mathrm{H}_{2} \mathrm{O}$. Sebanyak 2,277 g CTAB dilarutkan dalam $18,882 \mathrm{~g}$ akuades selama 30 menit pada temperatur $60^{\circ} \mathrm{C}$ dan didinginkan. Setelah itu ditambahkan $0,091 \mathrm{~g} \mathrm{Al}_{2} \mathrm{O}_{3}$. $\mathrm{Na}_{2} \mathrm{O}$ dan diaduk selama 30 menit. Kemudian sebanyak 7,512 $\mathrm{g} \mathrm{Na}_{2} \mathrm{SiO}_{3}$ ditambahkan tetes demi tetes dan dilakukan pemanasan pada temperatur $60^{\circ} \mathrm{C}$ selama 1 jam dengan diaduk sampai homogen dan didinginkan kembali. Selanjutnya $\mathrm{pH}$ campuran diatur sekitar $\mathrm{pH} 10$ dengan menambahkan asam asetat $1 \mathrm{M}$ dan dilakukan pengadukkan selama 2 jam. Campuran dimasukkan dalam autoklaf dan dipanaskan pada temperatur $100^{\circ} \mathrm{C}$ selama 24 jam. pH akhir campuran menunjukkan kenaikan sampai $\mathrm{pH}$ 11. Campuran disaring dan dicuci dengan akuades sampai netral kemudian dikeringkan dalam oven pada temperatur $100^{\circ} \mathrm{C}$ semalam. Kemudian MCM 41 dikalsinasi pada temperatur $550^{\circ} \mathrm{C}$ selama 5 jam. Hasil sintesis dikarakterisasi dengan difraksi sinar-X, dan Surface Area Analyzer dan uji kinetika adsorpsi terhadap metilen biru. 


\section{PEMBAHASAN}

\section{Karakter dan Parameter Al-MCM 41}

Sintesis Al-MCM 41 secara langsung bertujuan untuk memodifikasi permukaan silika pada kerangka MCM 41 dengan Alumina. Hal ini diharapkan mampu mengubah kerangka yang dihasilkan oleh MCM 41. Proses ini merupakan salah satu teknik modifikasi permukaan MCM 41. Penambahan alumina dalam sintesis langsung ini diharapkan akan menyebabkan terbentuknya situs negatif pada MCM 41 sehingga MCM 41 dapat digunakan dalam aplikasi yang lainnya. Proses perubahan kerangka MCM 41 dengan adanya alumina seperti yang diilustrasikan seperti Gambar 1.
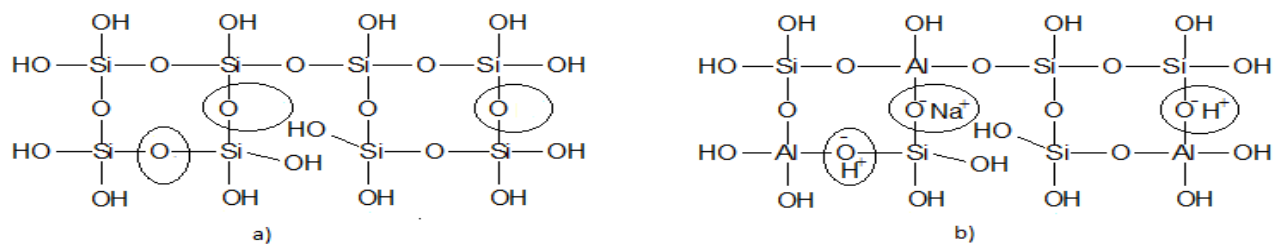

\section{Gambar 1. Ilustrasi kerangka permukaan MCM 41: a) Si-MCM 41 dan b) Al- MCM 41}

Hasil sintesis langsung MCM-41 memiliki karakter material dengan luas permukaan yang besar yaitu 995,513 m²/g dan diameter pori yang lebar yaitu 30,446 Å (Tabel I).

Tabel I. Karakter hasil sintesis Al-MCM 41

\begin{tabular}{|c|c|}
\hline Parameter (symbol, satuan) & Hasil Pengukuran \\
\hline 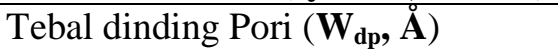 & 15,173 \\
\hline Volume Pori $\left(\mathbf{V}_{\mathbf{B J H},} \mathbf{c m}^{3} / \mathbf{g}\right)$ & 0,584 \\
\hline Diameter Pori $(\mathbf{D p}, \AA \mathbf{A})$ & 30,446 \\
\hline Luas Permukaan $\left(\mathbf{A}_{\text {BET }}, \mathbf{m}^{2} / \mathbf{g}\right)$ & 995,513 \\
\hline
\end{tabular}

Hasil analisis beberapa parameter MCM 41 pada Tabel I menunjukkan bahwa sintesis langsung Al-MCM 41dapat digunakan dalam salah satu aplikasi yaitu sebagai adsorben. Hal ini karena karakter Al-MCM 41 ini memiliki luas permukaan yang besar dan diameter pori yang lebar. Keberhasilan modifikasi MCM 41 dengan penambahan alumina dalam proses sintesis dapat dilihat pada peningkatan kapasitas adsorbsi Al-MCM 41 pada metilen biru sebesar 161,3 mg/g jika dibandingkan MCM 41 yang hanya sebesar 37,0 mg/g (Ahda, dkk., 2014). Sesuai seperti yang dilaporkan Lewandowski, dkk., (2013) yang menyimpulkan bahwa perbedaan yang besar dalam proses adsorpsi jumlah zat warna dapat dijelaskan karena adanya interaksi fisika kimia zat warna terhadap permukaan silika.

\section{Studi Kinetika Adsorpsi Terhadap Metilen Biru}

Kajian kinetika ini membahas tentang adsorpsi adsorben Al-MCM 41 dalam mengadsorpsi metilen biru. Kinetika adsorpsi Al-MCM 41 terhadap metilen biru dilakukan pada konsentrasi metilen biru $110 \mathrm{ppm}$ tanpa pengaturan $\mathrm{pH}$ sistem dan pada temperatur $27^{\circ} \mathrm{C}$. Hasil adsorpsi Al-MCM 41 terhadap metilen biru akan mencapai kesetimbangan setelah 120 menit (Gambar 2).

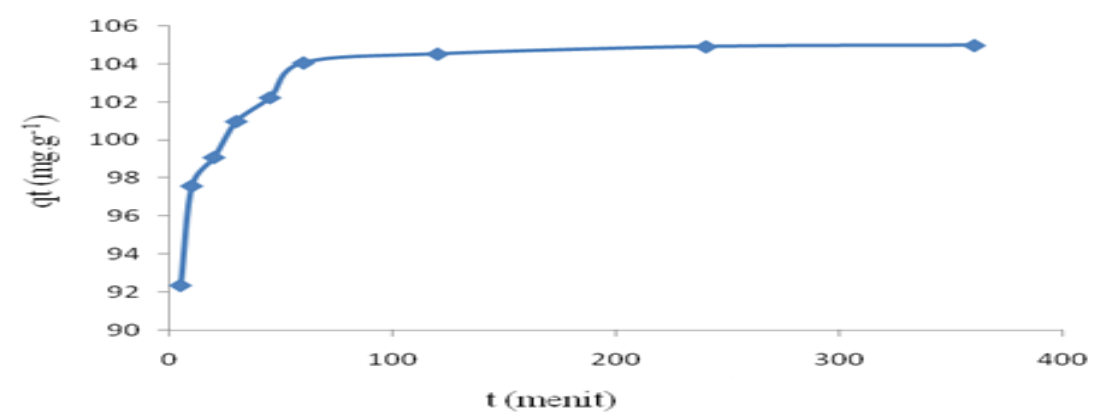

Gambar 2. Proses adsorpsi Al-MCM 41 terhadap metilen biru 
Karakterisasi adanya metilen biru yang teradsorpsi dapat diidentifikasi dengan menggunakan spektroskopi inframerah. Material Al-MCM 41 setelah dilakukan proses adsorpsi terhadap metilen biru terdeteksi munculnya puncak baru sekitar daerah bilangan gelombang sekitar $1350 \mathrm{~cm}^{-1}$ merupakan ciri bentuk vibrasi gugus metil $\left(-\mathrm{CH}_{3}\right)$. Indikasi serapan pada bilangan gelombang sekitar $1350 \mathrm{~cm}^{-1}$ menandakan bahwa metilen biru telah teradsorpsi pada material mesopori tersebut. Proses adsorpsi metilen biru pada MCM 41 dapat terjadi pada pada permukaan kerangka MCM 41 atau masuk menutupi pori-pori MCM 41. Penelitian terdahulu yang dilakukan oleh Lee dkk. (2007) melaporkan besarnya ukuran zat warna basa menyebabkan penutupan pori-pori berukuran kecil sehingga membuat tidak dapat diakses dan menghambat adsorpsi molekul nitrogen kedalam pori.

Fenomena ini menjadikan dasar bahwa proses adsorpsi sangat dipengaruhi oleh situs aktif pada adsorben. Hasil penelitian ini juga menjelaskan bahwa Al-MCM 41 tidak mengalami dealuminasi setelah proses adsorpsi. Spektra inframerah memperlihatkan serapan pada bilangan gelombang 957 $\mathrm{cm}^{-1}$ tidak mengalami pergeseran ke arah yang lebih besar sebagai indikasi terjadinya proses dealuminasi (Gambar 3). Hal ini sesuai dengan yang dikemukakan oleh Ryoo dan Jun (1997) bahwa MCM 41 tidak mengalami perubahan yang berarti bila berkontak dengan air pada temperatur kamar.

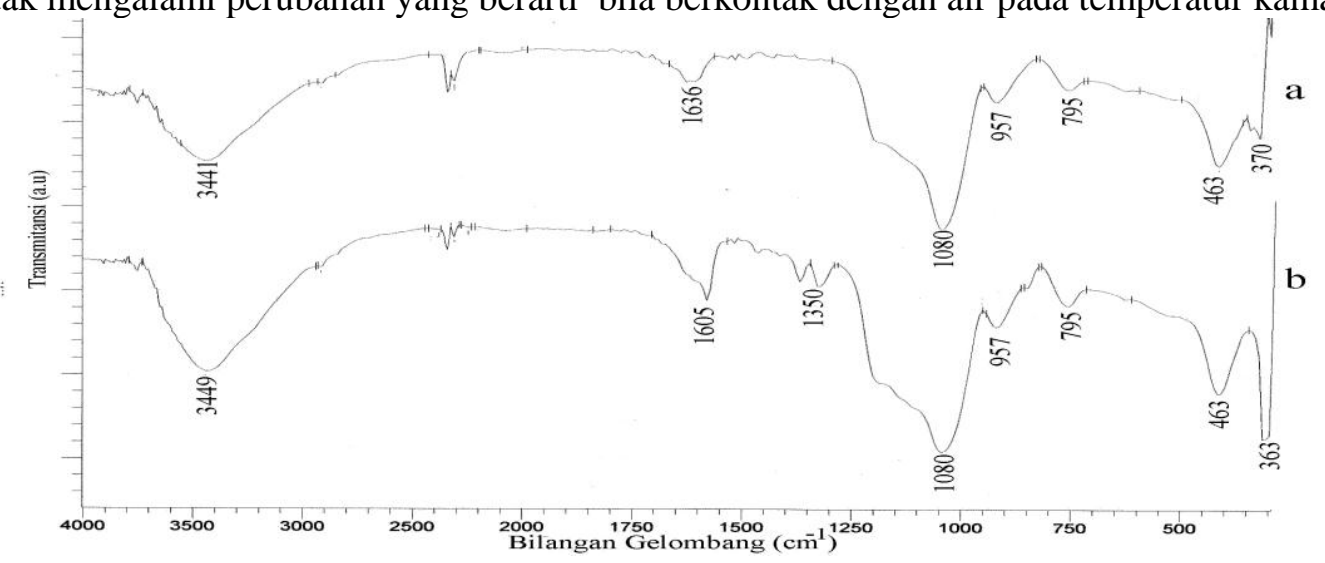

Gambar 3. Spektra inframerah Al-MCM 41: a) sebelum proses adsorpsi, b) setelah proses adsorpsi

Proses adsorpsi Al-MCM 41 tersebut kemudian dilakukan pengujian kinetikanya mengikuti terhadap orde satu atau orde dua, atau pseudo orde satu atau bahkan pseudo orde dua. Monash dan Pugazhenthi (2010) telah meneliti kinetika adsorpsi MCM 41 terhadap metilen biru dan hasil kinetika adsorpsinya mengikuti model kinetika pseudo orde dua. Penelitian ini mencoba mempelajari kinetika Al-MCM 41. Hasil persamaan kinetika adsorpsi Al-MCM 41 terhadap metilen biru dengan orde satu, orde dua, pseudo orde satu dan pseudo orde dua seperti Gambar 4 dan Gambar 5.
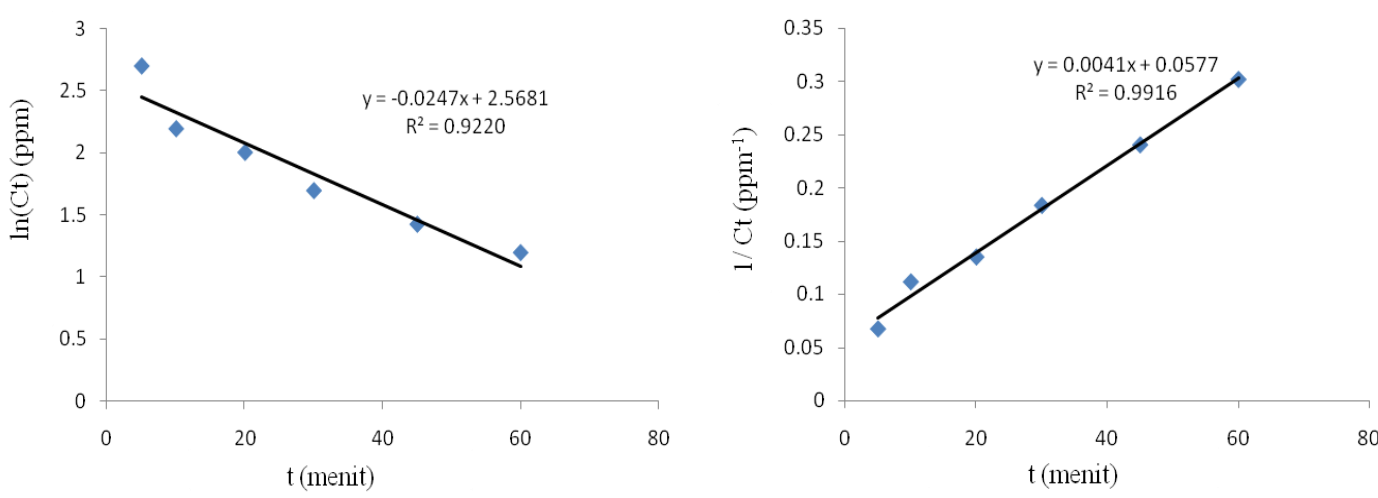

Gambar 4. Persamaan kinetika adsorpsi Al-MCM 41 terhadap metilen biru: persamaan kinetika orde satu (kiri) dan orde dua (kanan) 

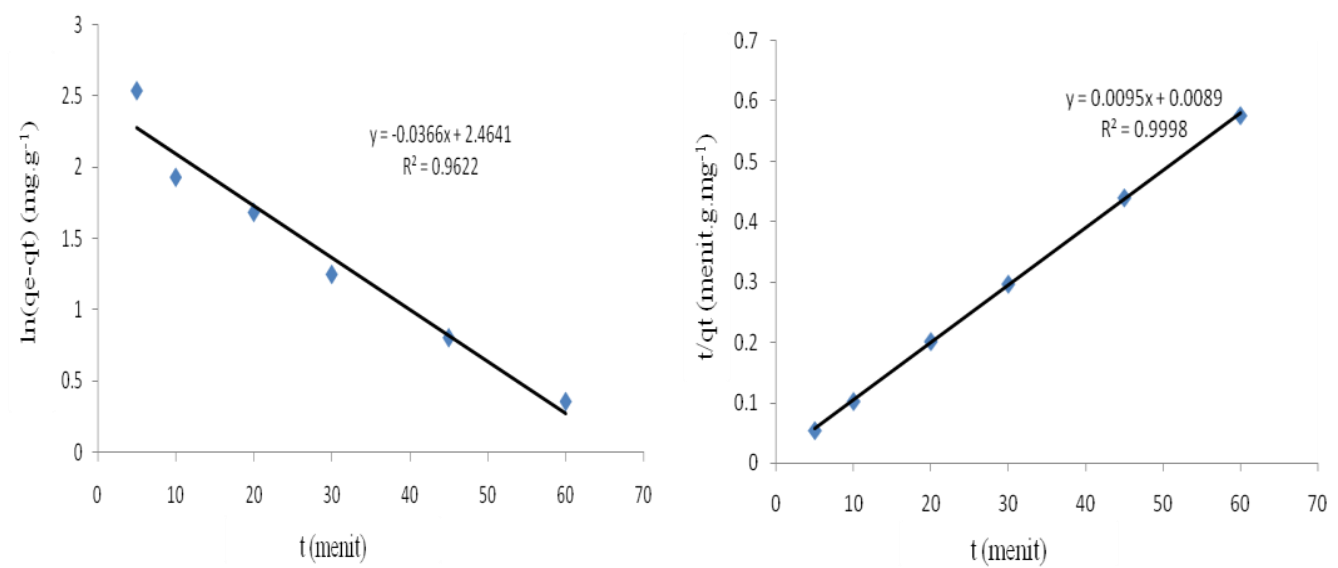

Gambar 5. Persamaan kinetika adsorpsi Al-MCM 41 terhadap metilen biru: persamaan kinetika pseudo orde satu (kiri) dan pseudo orde dua (kanan)

Persamaan orde satu, orde dua dan pseudo orde satu menghasilkan harga koefisien determinasi $\left(r^{2}\right)$ lebih rendah dari pada yang dihasilkan oleh persamaan pseudo orde dua. Oleh karena itu, kinetika adsorpsi Al-MCM 41 terhadap metilen biru mengikuti pseudo orde dua dengan nilai koefisien determinasi $\left(r^{2}\right)$ sebesar 0,999. Hasil kinetika adsorpsi Al-MCM 41 penelitian ini sesuai dengan hasil penelitian Boukoussa, dkk., (2013) yang menyimpulkan bahwa kinetika adsorpsi Al-MCM 41 terhadap zat warna kuning mengikuti model kinetika adsorpsi pseudo orde dua.

Tabel II. Konstanta laju adsorpsi Al-MCM 41 pseudo orde satu dan pseudo orde dua pada konsentrasi metilen biru 110 ppm

\begin{tabular}{|c|c|c|}
\hline Model Kinetika & Parameter & Nilai Parameter \\
\hline \multirow{3}{*}{ Pseudo orde satu } & $\mathbf{k}_{1}\left(\right.$ menit $\left.^{-1}\right)$ & 0,037 \\
\hline & $\mathbf{q}_{\mathrm{e} \text { (terhitung) }}(\mathrm{mg} / \mathrm{g})$ & 11,752 \\
\hline & $r^{2}$ & 0,962 \\
\hline \multirow{3}{*}{ Pseudo orde dua } & $k_{2}\left(\right.$ g.mg ${ }^{-1} \cdot$ menit $\left.^{-1}\right)$ & 0,010 \\
\hline & $\mathbf{q}_{\text {e (terhitung) }}(\mathbf{m g} / \mathbf{g})$ & 105,263 \\
\hline & $r^{2}$ & 0,999 \\
\hline
\end{tabular}

Hasil penelitian ini menunjukkan bahwa kinetika adsorpsi Al-MCM-41 terhadap metilen biru mengikuti pseudo orde dua dengan nilai koefisien determinasi $\left(r^{2}\right)$ sebesar 0,999 dan nilai konstanta laju adsorpsi Al-MCM-41 sebesar $10^{-2} \mathrm{~g} \mathrm{mg}^{-1}$. menit ${ }^{-1}$ (Tabel II).

\section{KESIMPULAN}

Hasil karakterisasi Al-MCM 41 memiliki tebal dinding Pori 15,173 $\AA$,Volume Pori 0,584 $\mathrm{cm}^{3} / \mathrm{g}$, Diameter Pori 30,446 Å, Luas Permukaan 995,513 $\mathrm{m}^{2} / \mathrm{g}$. Hasil kinetika adsorpsi Al-MCM 41 terhadap metilen biru mengikuti kinetika adsorpsi pseudo orde dua dengan nilai koefisien determinasi $\left(r^{2}\right)$ sebesar 0,999 dan nilai konstanta laju adsorpsi Al-MCM-41 sebesar $10^{-2}$ g.mg ${ }^{-1} \cdot$ menit $^{-1}$.

\section{DAFTAR PUSTAKA}

Ahda, M., Sutarno, dan Kunarti, E.S., 2014, Sintesis Langsung Untuk Modifikasi Permukaan Mcm-41 Dengan Alumina Dan Aplikasinya Dalam Adsorpsi Metilen Biru, Prosiding Seminar Nasional dan Workshop ”Perkembangan terkini Sains Farmasi dan Klinik IV, 140-147. 
Boukoussa, B., Hamacha, R., Morsli, A., Bengueddach, A., 2013, Adsorption of yellow dye on calcined or uncalcined Al-MCM-41 mesoporous materials, Arabian Journal of Chemistry, $1-10$

Das, D., Tsai, C.M., and Cheng, S., 1999, Improvement of hydrothermal stability of MCM-41 mesoporous molecular sieve, Chem. Commun, 473-474.

Ho, Y.S., 2006, Review of Second-order Models for Adsorption Systems, J.Hazard. Mater., B, 136, 681-689.

Ho, Y.S. and Mckay, G., 1999, The Sorption of Lead (II) Ions on Peat, Wat. Res., 33 (2), 578-584.

Kim, J.M., Kwak, J.H., Jun, S., and Ryoo, R., 1995, Ion Exchange and Thermal Stability of MCM-41, J. Phys. Chem., 99 (45), 16742-16747.

Lee, C.K., Liu, S.S., Juang, L.C., Wang., C.C., Lin, K.S., and Lyu, M.D., 2007, Aplication of MCM41 for Dyes Removal from Wastewater, J.Hazard. Mater., 147, 997-1005.

Lewandowski, D., Olejnik, A., Schroeder, G., 2014, Adsorption studies and release of selected dyes from functionalized mesoporous MCM-41 silica, Cent. Eur. J. Chem., 12 (2), 233-241.

Monas, P., and Pugazhenthi, G., 2010, Investigation of equilibrium and kinetic parameters of methylene blue adsorption onto MCM-41, Korean J. Chem. Eng., 27, (4), 1184-1191.

Park, S.H., Kim, B.H., Selvaraj, M., and Lee, T.G., 2007, Synthesis and characterization of mesoporous Ce-Mn-MCM-41 molecular sieves, J. Ind. Eng. Chem., 13 (4), 637-643.

Ryoo, R., and Jun, S., 1997, Improvement of Hydrothermal Stability of MCM-41 using Salt Effects during the Crystallization Process, J. Phys. Chem. B, 101, 317-320. 